López Martínez, Irene.

Alumna de la Escuela Internacional de Doctorado de la Universidad de Murcia, Facultad de Letras.

\title{
Matadero Memoria Aural: cartografiando en abierto las transformacionoes urbanisticas de Arganzuela.
}

\section{Matadero Memoria Aural: an open cartography of urban transformations in Arganzuela.}

\author{
TIPO DE TRABAJO: \\ Comunicación. \\ PALABRAS CLAVE: \\ Cartografía, memoria, ciudad, comunidad.
}

KEY WORDS:

Cartography, memory, city, community.

\section{RESUMEN.}

El presente texto pretende analizar el proyecto Matadero Memoria Aural (MMA) realizado por el colectivo Sound Readers para ejemplificar el reciente fenómeno de iniciativas artísticas que aúnan la investigación y la creación para la realización de diferentes archivos de diversa naturaleza, que tienen como objetivo la visualización y visibilización de relatos alternativos. En este caso MMA tenía el objetivo de recuperar la memoria oral del antiguo Matadero Municipal de Madrid.

\section{ABSTRACT.}

The aim of the essay is to analyze Matadero Memorial Aural project launched by Sound Readers as an example of the recent phenomenon of artistic initiatives that want to bring together the creation and researching whose intend is to visualize the alternative storytelling's. In this case, MMA is a web-based sound project bases on a new perspective on the history and memories of Madrid's municipal slaughterhouse and its immediate surroundings in the Arganzuela district.

\section{CONTENIDO}

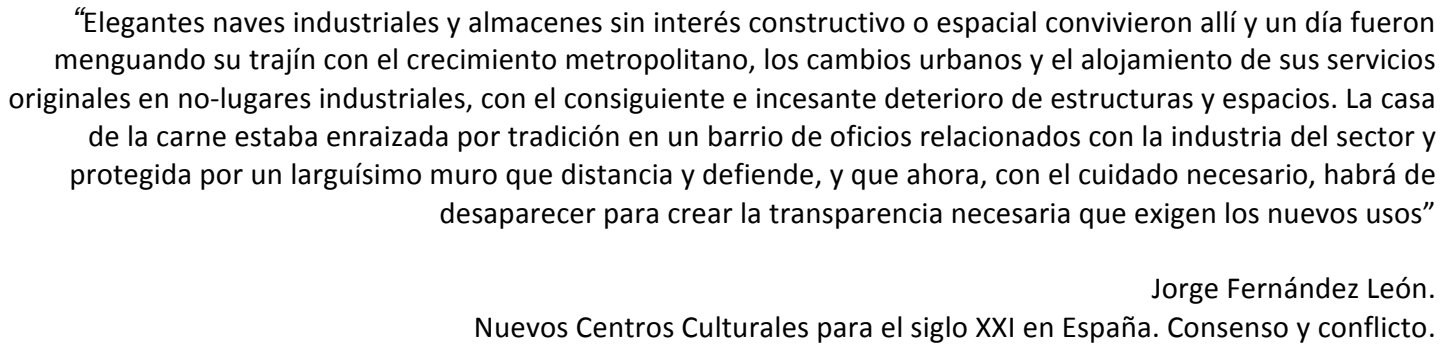


El Matadero tildaba a desaparecer... Se empezaron a hacer mataderos de zona (Leganés, San Agustín de Guadalix), sobre todo el porcino y en el lanar fue quitando mucho trabajo aquí. Empezó a decaer... Había que hacer muchas inversiones en el sentido de la Comunidad Europea y como no se hicieron pues se cerró. Se llegó a un acuerdo... a unos nos recalificaron a otros los jubilaron. Unos pa bien otros pa mal... Tienes que subsistir... Y esa es la historia de este Matadero que todavía sigue con su nombre bonito de Matadero de Madrid.

Pedro, matarife.

\section{INTRODUCCION.}

En los últimos años se asiste a una proliferación de iniciativas artísticas que utilizan la creación sonora como herramienta de interpretación de la realidad urbana y sus transformaciones, ya sean políticas, sociológicas, espaciales etc. En todos ellos, existe una clara voluntad de mediación tecnológica entre la realidad física de un espacio determinado con la realidad digital, puesto que son, en su mayoría, plataformas digitales donde se encuentran disponibles los materiales. Así, las cartografías y los mapas sonoros funcionan como repositorio donde los archivos pueden consultarse de manera libre. Además, este tipo de mapas responden ante el paradigma de la cultura libre, que suelen decantarse por licencias creative commmons, es decir, son contenidos disponibles para libre descarga y escucha, de manera que pueden ser compartidos, hackeados, remezclados e incluso, en algunas plataformas, se hacen de manera colaborativa.

Así, existen, desde los últimos años proyectos de practica e investigación artística que tienen como objetivo cartografiar y mapear las transformaciones urbanas a través de la dimensión sonora y que se valen de las plataformas digitales y geolocalización como método de materialización de los resultados.

Se pueden nombrar varios ejemplos que responden a estas características, los llevados mapas sonoros colaborativos llevados a cabo por el colectivo Escoitar, o también el proyecto Yes We Klang, mapa sonoro de la \#spanishrevolution promovido por Mediateletipos solo por citar algunos. Sin embargo, voy a analizar uno de estos proyectos, Matadero Memoria Aural, como catalizador de los leits motivs nombrados ya que responden a varios ámbitos, como el sonoro, el nemónico, el arquitectónico y el urbano, que hacen que lo definan como un proyecto de naturaleza interdisciplinar y que puede ser exponente de este fenómeno de iniciativas artísticas cuyo objetivo es la representación cartografía por medio de las herramientas tecnológicas y digitales.

\section{MATADERO MEMORIA AURAL.}

Matadero Memoria Aural fue un proyecto creado por el colectivo Sound Readers con el objetivo de rastrear la memoria del antiguo Matadero Municipal a través de entrevistas orales a las personas que desde los años 30 en adelante, habían estado implicados tanto en el edificio como en su entorno limítrofe. Para hacer accesible todo el material recopilado, se creó un archivo web donde las entrevistas, -algunas de ellas realizadas a la manera del sound walk o paseos sonoros, para recorrer y cuestionar el territorio- y piezas sonoras se encuentran geolocalizadas en un mapa para que cualquiera pueda escucharlas desde casa o in situ.

Uno de los propósitos del proyecto era buscar las raíces industriales e indagar en el pasado y la memoria del antiguo Matadero de Madrid desde la perspectiva del sonido. La razón de elegir esta dimensión y no otro respondía a dos cuestiones. La primera era obvia: no se había hecho desde que el Matadero se abrió como centro de cultura contemporánea, nada relativo a la memoria y sonido (a excepción de Muta Matadero, un encargo ex profeso del Ayuntamiento de Madrid al colectivo Nophoto sobre la historia visual del mismo). La segunda es que el arte sonoro ha sido, en la historia del arte, la disciplina menos visible pero que ahora exige y reivindica con pleno derecho su papel en la herencia cultural artística.

Para llevar a cabo dicho propósito había que realizar una trabajo de campo y mediación para buscar, casi como detectives, a las personas que habían estado involucradas en la historia de Matadero en sus diversas facetas; o bien habían trabajado en el Matadero Municipal como matarifes, mondongueros etc, o bien habían vivido en el barrio, o habían tenido un negocio. Tampoco se quiso dejar de contar con las voces del presente de Matadero: los actuales trabajadores -gestores, mediadores, técnicos-, los nuevos vecinos y finalmente arquitectos de las diversas reformas -aunque sólo pudimos entrevistar a los que accedieron a colaborar en el proyecto-.

La tarea de mediación y de trabajo de campo se prolongó durante siete meses, durante los cuales se estableció una metodología rigurosa basada en entrevistas con preguntas idénticas pero flexibles, a veces incluso entrevistando varias veces a las mismas personas, para poder reconstruir la historia del barrio. También se incluyó las soundwalk, o lo que es lo mismo: entrevistas grabadas mientras se recorre el espacio del que se está hablando, en este caso, Matadero y Legazpi. Lo que recuerda por un lado a la 
figura del paseante o flâneur en su dimensión post-industrial, y por otro, al movimiento como cuestionamiento crítico que posibilita el ejercicio de la memoria. Una influencia recibida de Toby Butler y sus memoryscapes.

La metodología de trabajo adoptado fue complicada y ardua, puesto que se disponía de muchas horas de material recopilado, por lo que se puso en marcha un dispositivo de trabajo en cadena que abarcó desde las transcripción de las entrevistas, la división por lugar geográfico con el objetivo de poder geolocalizar el material correctamente en un mapa digital, el análisis de la información creando varias categorías o tags que facilite la comprensión del contenido, la edición y limpieza del sonido, la creación de pequeños resúmenes de las entrevistas, entre otros asuntos. Para poder acceder a toda esta información, se creó un archivo web ${ }^{1}$ donde se encuentran geolocalizadas en un mapa las diferentes entrevistas y los paseos sonoros, además de piezas sonoras de carácter más experimental.

La idea era poder exhibir el proyecto en los lugares donde se había grabado las entrevistas y donde se había recorrido, de la mano de vecinos, el barrio de Legazpi. Esta estrategia respondía a una suerte de palimpsesto que pretendía conectar el pasado con el presente, creando una instalación sonora en la que Matadero y sus alrededores cobrasen vida para ser transmisores de la memoria urbana del lugar. Interesante es escuchar, a la misma vez que se pasea, a Lina, vecina del barrio desde hace cuarenta años, que relata las diferentes transformaciones urbanísticas del Río Manzanares (Madrid Río ahora) cuando eran las huertas y los árboles los que dominaban el paisaje, o cuando, después de la Guerra Civil, eran los presos políticos convertidos en obreros forzados los que picaban piedra de sol a sol. Especialmente emotivo es escuchar a Juan y Ramón, dos mondongueros que relatan los días de trabajo en las diferentes naves de Matadero, y recuerdan por ejemplo, cómo calentaban su ropa mojada en la caldera, o cómo las pocas mujeres que trabajaban allí, se encargaban de elaborar las panzas de los corderos. También, Alfredo, otro vecino de Legazpi que nos lleva a recorrer, casi en una aventura distópica debordiana, el rastro de las fábricas industriales que una vez fueron prominentes epítomes del progreso.

\section{ESPACIOS QUE HABLAN.}

Una de las dimensiones que MMA supuso, fue la de abordar y complejizar el espacio arquitectónico, para lo que había que acometer el estudio del edificio en relación a su historia reciente de Matadero como epicentro industrial en Madrid y su evolución a centro de creación actual.

En primer lugar, la reconversión de antiguos espacios y fábricas industriales en museos y centros de arte es un fenómeno ampliamente practicado; países europeos como Inglaterra, Alemania o Italia han sabido articular y reaprovechar su pasado industrial en contenedores de cultura que son ejemplo de la más sofisticada gentrificación y apropiacionismo simbólico del pasado. Así lo cuenta Olga Fernández: "desde principios de los años 80 , las colecciones minimalistas y posminimalistas, a las que pronto se unieron otro tipo de colecciones, empezaron a ocupar en Europa las ruinas rehabilitadas de espacios históricos abandonados, fábricas vacías y otros edificios de antiguo uso industrial”2 .

En España nos sumamos a la moda hace relativamente poco. Una lista podría incluir nombres como La Conservera en Murcia, (gran apuesta presupuestaria venida a menos) Laboral en Gijón, Tabakalera en versión vasca (que después de un tiempo en barbecho ha retomado su andadura) y madrileña (donde conviven la autogestión asamblearia con el Ministerio de Cultura).

Matadero como centro de creación contemporánea se abrió en 2007 aunque ha sufrido una rehabilitación que se ha dilatado en el tiempo. En términos generales, planea el respeto hacia la primigenia construcción industrial dejando materiales visibles, fachadas intactas y enfatizando en ciertos lugares como las antiguas naves de exposición de ganado (naves 15 y 16) esa prominente idea de arquitectura industrial visible por ejemplo, en los conductos que ondean el techo.

No en vano, todo el conjunto de Matadero consiguió en 2012 el premio FAD de Arquitectura, y de manera específica la "Nave de la Música” del estudio Langarita-Navarro, obtuvo la mención especial de Arquitectura Emergente Mies Van der Rohe 2013. Sin duda, la intervención que más relación y respeto guarda con la memoria de Matadero.

En segundo lugar, se debe analizar la relación espacial y diálogo que establecen estas antiguas fábricas reformadas, donde predomina una fetichización del espacio, una imposición del objeto de culto, imperando, casi a la fuerza, la cosificación de la arquitectura. Puede llegarse a pensar que la estetización del espacio conlleva una pleitesía a la historia del edificio, sin embargo, lo que consigue es el efecto contrario: la anulación y la desactivación del pasado al ser transformado en objeto de veneración.

\footnotetext{
${ }^{1}$ http://mma.soundreaders.org/

2 Fernández López, Olga, "Travesía Site specif. Institucionalidad e imaginación" en Villa, Manuela et al: 11 artistas en una cámara frigorífica conversaciones sobre la práctica sitio específico, Madrid: Matadero Madrid: Teatro Fernán Gómez-Centro de Arte,2011.
} 
Un ejemplo claro de culto hacia el espacio es la antigua cámara frigorífica incinerada en los años 90 -cuando ya había cesado la actividad industrial- y que no se ha intervenido para conservar la potencia estética que los restos del incendio le confieren. Por ese motivo se ideó Abierto x obras una iniciativa de coordinación que plantea obras de carácter site specif, es decir, pensadas exclusivamente para tan peculiar espacio. La mayoría de las obras que se han expuesto a lo largo de los años que lleva activo el programa, han reflexionado sobre el espacio en cuestiones materiales, lumínicas, sonoras, paisajísticas, etc.

Sin embargo, aunque estas obras efímeras siempre tengan en cuenta el diálogo con el lugar que las acoge, a veces pueden caer o bien en otorgarle excesivo protagonismo al espacio en su dimensión antropológica o fenomenológica, así lo argumenta Richard Williams ${ }^{3}$ al examinar las políticas de reconversión de antiguas fábricas transformadas en museos y centros de arte como Tate Modern en Londres o el Tramway en Glasgow, o bien en la instrumentalización de la memoria servida a fines políticos, como alertaba Andreas Huyssen ${ }^{4}$.

\section{COMUNIDADES MOVEDIZAS.}

En tercer lugar, y siguiendo con el hilo argumental que busca indagar en las dimensiones arquitectónicas, espaciales y comunitarias de Matadero en correspondencia con su pasado, cabe preguntarse por la relación con el territorio circundante, el barrio y su historia. Este tipo de ejercicios de acercamiento y mediación con diferentes comunidades suele ser responsabilidad de Intermediae, un espacio de producción híbrido donde se experimenta con protocolos de inclusión hacia la ciudadanía. El abanico, como se puede imaginar, es demasiado amplio y no siempre se pueden incluir todas las colectividades de la paleta social y artística.

En este punto cabría preguntarse ¿dónde queda la comunidad que durante buena parte del siglo pasado ha pertenecido y ha construido simbólicamente Matadero y su entorno? Desde MMA, se quería responder a esta cuestión, gracias al relato polifónico conformado por los vecinos y antiguos trabajadores del Matadero, en el que salió a relucir que Matadero era uno de los actores principales de la industria del barrio, pero no el único. Estaba el Mercado de frutas y verduras (actual EVA) que se mantuvo activo hasta la década de los ochenta. Estaban los transportistas, camioneros, repartidores, y los negocios relacionados con esta actividad comercial: pensiones, agencias de transporte....Estaban las fábricas de Arganzuela como la Siderúrgica, la Papelera y la de Coca Cola, entre otras. Y estaba el propio barrio en cuestión que se nutría y se alimentaba gracias a esta estructura económica, creando sus formas de vida, su idiosincrasia, sus reglas de juego: común entre los lugareños era ir a bailar el pasodoble a La Leonesa, ir a merendar al río, jugar en los campos de huertas..

Toda esa comunidad que en algún punto de su vida ha formado parte del imaginario Matadero, sigue existiendo y recordando, dando voz al pasado: Antonio del bar La Alcubilla, los pocos matarifes que siguen reuniéndose todos los jueves por la mañana, La casa del Reloj que alberga el Centro de Mayores del distrito de Arganzuela donde acuden los vecinos del barrio que viven en sitios míticos de Legazpi como el Pico del pañuelo...

Aunque, por otro lado, sea lógico que las transformaciones urbanísticas generen un nuevo mapa relacional y social de un determinado barrio, no por ello se debe obviar su historia, sino que ha de convivir como un palimpsesto donde una capa se superpone con la otra y coexisten en cada presente "las dimensiones temporales del pasado y del futuro en relación" ${ }^{5}$.

En este caso, con el desmantelamiento de las fábricas, de los comercios, y de la industria en general, y la "hausmanización de la ribera del Manzanares" ${ }^{\prime \prime}$, ha propiciado que el barrio haya adoptado nuevos usos y costumbres y que haya migrado su identidad primigenia, un fenómeno que casi la totalidad de los vecinos entrevistados recalca en sus testimonios, sobre todo lo referido a las "nuevas vecindades latinoamericanas".

A este respecto, habría que señalar la importancia que adquiere para MMA el concepto de memoria colectiva postulado por Maurice Halbwachs que la define como una comunidad unida por un pasado común en un espacio físico. Por lo tanto, a pesar de las políticas institucionales y urbanísticas, la memoria colectiva de Legazpi y por ende Matadero, continúa latente.

Decía Walter Benjamin en sus tesis sobre la filosofía de la historia, que "de todo lo que sucedió alguna vez, nada debe considerarse perdido para la Historia". Ahora quedaría, para la consumación del éxito de MMA, no dejar morir los afectos y la conexión que tantos meses costó construir y que se generaron gracias a la enorme voluntad y gratitud por parte de los entrevistados, evitando caer, de este modo, en las prácticas relacionales que hacen mal uso de las lógicas de participación y voluntarismo.

\footnotetext{
${ }^{3}$ Williams, Richard "Remembering, forgetting and the industrial gallery space", en Crinson, Mark: Urban Memory. History and amnesia in the modern city, Nueva York: Routledge, 2005

${ }^{4}$ Huyssen, Andreas, En busca del futuro perdido. Cultura y memoria en tiempos de globalización, Buenos Aires: Fondo de Cultura Económica, 2002.

${ }^{5}$ Koselleck, Reinhart, Le futur passé. Contribution à la sémantique des temps historiques Paris, Editions de l'ehess, 1990 citado por DidiHuberman, George, Ante el tiempo. Historia del Arte y anacronismo de las imágenes,Buenos Aires: Adriana Gil Editora, 2008, p. 65

${ }^{6}$ Carrillo, Jesús, Las nuevas fábricas de la cultura: los lugares de creación y la producción cultural en la España contemporánea. Consultado en: medialab-prado.es/mmedia/689
} 
Un último apunte sería mencionar, casi de manera anecdótica, el relevo que se ha producido en estos recientes años, de la antigua industria por una nueva industria, la cultural. A día de hoy, y por poner un ejemplo concreto, la iniciativa Factoría Cultural ha creado un espacio de coworking creativo y de emprendedores donde se debe pagar una pequeña pero no anecdótica cantidad de dinero por usar el espacio de gestión pública y formar parte de esta creciente comunidad emprendedora. Sólo espero que esta nueva vertiente en el uso de los espacios creativos y musealizados no contribuya a olvidar, menospreciar o anular la vida pasada de los barrios y que la máquina gentrificadora no aplaste la identidad de los lugares.

\section{CONCLUSION.}

A través del análisis del proyecto Matadero Memoria Aural, se ha querido señalar la importancia de este tipo de iniciativas que se sitúan a caballo entre la investigación y la creación, en las representaciones de la realidad urbana y social de la contemporaneidad gracias a las nuevas herramientas digitales que posibilitan la creación de este tipo de proyectos que, sin una traslación y mediación virtual, tendrían problemas de materializarse. Herramientas como UMapper o Meipi permiten, de forma colaborativa, crear mapas ya sean sonoros, geográficos...que representan la realidad y permiten la creación de un relato alternativo de la realidad que nos rodea, visualizando conflictos, exponiendo historias no contadas, señalado realidades invisibles etc. En este sentido, MMA fue uno de tantos proyectos que ha tenido como objetivo contar, de la mano de las personas que vivieron y habitaron el barrio, las transformaciones acontecidas que dieron lugar a un espacio contenedor de cultura, que en la actualidad se expone como esencial en la configuración de la gestión cultural municipal y estatal y que aún a día de hoy, sigue ocasionado conflictos. Sin ir mas lejos, hace unas semanas se presentaba la nueva programación de las antiguas naves del Español, rebautizadas como Naves Matadero Centro Internacional de Artes Vivas, con una gran polémica por la naturaleza del contenido perfomático de la nueva programación y que ha sido representada por la imagen de un pequeño cordero.

Si al principio de este texto se aludía a la posibilidad de que estos proyectos pudieran ser hackeados, replicados, como una suerte de prototipo con el que experimentar, ahora mismo MMA está siendo replicado en Valladolid, de la mano del Laboratorio de las Artes (Bit:LAV) está realizando un proyecto de características similares que recupera la antigua memoria del Matadero municipal de esta ciudad. Con esto, el cometido de MMA se ha cumplido, posibilitar la circulación del conocimiento y abrir una brecha donde el presente se enfrente a su pasado, para que no olvidemos que la idiosincrasia y memoria urbana también deben ser rescritas, reinterpretadas, puestas en cuestionamiento. 